\title{
Streptozotocin-induced diabetic mice exhibit reduced experimental choroidal neovascularization but not corneal neovascularization
}

\author{
GAOQIN LIU ${ }^{1,2}$, LEI CHEN ${ }^{1}$, QINHUA CAI ${ }^{1}$, HONGYA WU $^{2,3}$, ZHIGANG CHEN ${ }^{1}$, \\ XUEGUANG ZHANG ${ }^{2,3}$ and PEIRONG LU ${ }^{1,2}$ \\ ${ }^{1}$ Department of Ophthalmology; ${ }^{2}$ Jiangsu Key Laboratory of Clinical Immunology; \\ ${ }^{3}$ Jiangsu Key Laboratory of Gastrointestinal Tumor Immunology, \\ The First Affiliated Hospital of Soochow University, Suzhou, Jiangsu 215006, P.R. China
}

Received February 20, 2018; Accepted July 17, 2018

DOI: $10.3892 / \mathrm{mmr} .2018 .9445$

\begin{abstract}
The present study aimed to investigate the effects of diabetes mellitus (DM) on the generation of experimental corneal neovascularization (CrNV) and choroidal neovascularization (ChNV). Diabetes was induced in mice by intraperitoneal injection of streptozotocin (STZ). Experimental $\mathrm{CrNV}$ and $\mathrm{ChNV}$ were induced by alkali injury and laser photocoagulation, respectively. $\mathrm{CrNV}$ and $\mathrm{ChNV}$ were compared between the STZ-induced diabetic mice and control mice two weeks after injury. Relative expression of angiogenic factors was quantified by reverse transcription-quantitative polymerase chain reaction, and progenitor cell or macrophage accumulation in the early phase following injury was examined by flow cytometric analysis. Compared with the alkali-injured normal mice, the alkali-injured diabetic mice (STZ-induced) exhibited no significant difference in CrNV occurrence, whereas the laser-injured diabetic mice exhibited significantly reduced levels of ChNV compared with those of the laser-injured control animals. The laser-induced intrachoroidal mRNA expression levels of angiogenic factors, including vascular endothelial growth factor, hypoxia-induced factor- $1 \alpha$, chemokine (C-C motif) ligand 3, and stromal cell-derived factor-1 $\alpha$, were reduced in the laser-injured diabetic mice when compared with laser-injured control mice. Furthermore, the laser-induced intrachoroidal infiltration of $\mathrm{c}-\mathrm{Kit}^{+}$ progenitor cells was impaired in the laser-injured diabetic mice compared with the laser-injured control mice. Overall, diabetes did not exert a significant effect on the generation of experimental CrNV. However, diabetes reduced laser-induced
\end{abstract}

Correspondence to: Professor Peirong Lu, Department of Ophthalmology, The First Affiliated Hospital of Soochow University, 188 Shizi Street, Suzhou, Jiangsu 215006, P.R. China E-mail: lupeirong@suda.edu.cn

Key words: corneal neovascularization, diabetes, choroidal neovascularization, angiogenesis, chemokine
ChNV through downregulation of intrachoroidal progenitor cell infiltration and angiogenic factor expression.

\section{Introduction}

Diabetes mellitus (DM) is a metabolic disease characterized by abnormal glucose metabolism (1). The disease can cause a number of complications that affect the quality of life of patients $(2,3)$. Patients with diabetes and abnormal glucose metabolism in their tissues and organs may exhibit enlarged blood vessels and microvascular dysfunctions (4,5). Diabetes also causes metabolic cataracts and ocular neovascular diseases such as advanced diabetic retinopathy (DR), which can result in serious eye damage and loss of vision.

The normal cornea is characterized by the absence of blood vessels and hematopoietic cells, including erythrocytes and leukocytes (6), and corneal avascularity is required for optical clarity and maintenance of vision. Corneal neovascularization (CrNV) results from numerous causes, including corneal infections, misuse of contact lenses, chemical burns, and inflammation, and can lead to severely impaired vision (7-9). In most cases of inflammation-induced $\mathrm{CrNV}$, bone marrow-derived progenitor cells, neutrophils, and macrophages infiltrate the cornea. Any effects on this infiltration may change the relative expression of cytokines and chemokines, and thereby affect the generation of CrNV (10-13).

Age-related macular degeneration (AMD) is a type of macular degeneration disease characterized by loss of central vision. The incidence rate increases with age. Wet AMD, characterized by choroidal neovascularization (ChNV), can result in seriously damaged central vision. It is believed that diabetes can cause DR, which is characterized by retinal neovascularization. However, it remains unclear whether diabetes has an effect on other types of ocular neovascularization such as CrNV or ChNV.

In the present study, streptozotocin (STZ)-induced diabetic mice were subjected to alkali injury-induced experimental $\mathrm{CrNV}$ and laser-induced experimental $\mathrm{ChNV}$, which are the optional models of CrNV and AMD (10-15), in order to examine the effects of diabetes on the development of ocular 
neovascularization. A greater understanding of the effects of diabetes on ocular neovascularization may not only enable prevention of various complications of diabetes, but also facilitate control of the development of ocular neovascularization diseases such as wet AMD.

\section{Materials and methods}

Reagents and antibodies. Sodium hyaluronate (HA) (cat. no. S0780000) and Avertin (cat. no. T48402) were purchased from the Sigma-Aldrich (Merck KGaA, Darmstadt, Germany). Alexa Fluor 488 donkey anti-rat IgG (H+L) antibody (cat. no. A-21208) was purchased from Invitrogen (Thermo Fisher Scientific, Inc., Waltham, MA, USA). Rat anti-mouse cluster of differentiation (CD) 31 (cat. no. MEC13.3) monoclonal antibodies (mAbs) were purchased from BD Biosciences (Franklin Lakes, NJ, USA). FITC-labeled rat anti-mouse F4/80 mAb (cat. no. ab105155) was acquired from Abcam (Cambridge, UK). Goat anti-mouse c-Kit (cat. no. AF1356) antibody, goat anti-chemokine (C-C motif) ligand (CCL) 3 (cat. no. AB-450-NA) and horseradish peroxidase-conjugated rabbit anti-goat secondary antibody (cat. no. 5160-2504) were supplied by R\&D Systems (Minneapolis, MN, USA). PE-labeled rabbit anti-goat IgG antibody (cat. no. SA5-10079) was purchased from Invitrogen (Thermo Fisher Scientific, Inc.). Goat anti-stromal cell-derived factor (SDF)-1 $\alpha$ (cat. no. sc-7427), goat anti-vascular endothelial growth factor (VEGF; cat. no. sc-152-G), goat anti-hypoxia-induced factor (HIF)-1 $\alpha$ (cat. no. sc-12542) and goat anti-GAPDH (cat. no. sc-48166) antibodies were from Santa Cruz Biotechnology, Inc. (Dallas, TX, USA).

Animals. All animal experiments followed the Guideline for the Care and Use of Laboratory Animals of the Chinese Medical Academy and were approved by the Soochow University Animal Care Committee (Suzhou, China), and were performed in accordance with the ARVO Statement for the Use of Animals in Ophthalmic and Vision Research. Specific pathogen-free four-week-old male BALB/c ( $n=90$; aged 4-5 weeks; weighing 10-15 g) or C57BL/6 mice ( $\mathrm{n}=210$; aged 4-5 weeks; weighing 10-15 g) were obtained from Shanghai SLAC Laboratory Animal Co. Ltd. (Shanghai, China), and were kept in our animal facility under specific pathogen-free conditions. A 12-h day/12-h night cycle was maintained during the entire course of the study. Animals were kept in groups of five and fed regular lab chow and water ad libitum. BALB/c mice were divided into two groups: An alkali-injured control group, where citrate-citric acid buffer was injected intraperitoneally and alkali was applied topically onto the cornea; and an alkali-injured diabetes group, where STZ was injected intraperitoneally and alkali was applied topically onto the cornea. C57BL/6 mice were also divided into two groups: A laser-injured control group, where citrate-citric acid buffer was injected intraperitoneally and laser treatment was performed on the retina; and a laser-injured diabetes group, where STZ was injected intraperitoneally and laser treatment was performed on the retina. Control animals were those injected with the vehicle, citrate-citric acid buffer.

Induction of diabetes in mice. Five-week-old male specific pathogen-free $\mathrm{BALB} / \mathrm{c}$ or $\mathrm{C} 57 \mathrm{BL} / 6$ mice were injected intraperitoneally with $50 \mathrm{mg} / \mathrm{kg}$ STZ (STZ mixed anomers; Sigma-Aldrich; Merck KGaA) diluted to $10 \mathrm{mg} / \mathrm{ml}$ with cold, pH 4.5 citrate-citric acid buffer (Sigma-Aldrich; Merck KGaA), as previously described (16-18). Briefly, STZ was reconstituted in $25 \mathrm{mM}$ citrate-citric acid buffer. Injections were administered intraperitoneally within $15 \mathrm{~min}$ of preparation. Mice were treated with five consecutive daily injections (10 mg/kg streptozotocin per day). Blood glucose levels were measured once a week, following the initial administration of STZ using a blood glucose monitor (OneTouch ${ }^{\circledR}$ Basic glucometer; LifeScan, Inc., Milpitas, CA, USA) drawing blood from the tail vein. Animals were considered diabetic if their blood glucose levels were $>11.1 \mathrm{mmol}(200 \mathrm{mg} / \mathrm{dl}) 4$ weeks after initial MLD (multiple low-dose)-STZ injection. Control animals received an equal amount of citrate-citric acid buffer under similar conditions (blood glucose: 5 +/- $0.4 \mathrm{mmol}$ ).

Alkali injury-induced $C r N V$. Specific pathogen-free nine-week-old BALB/c mice were anesthetized with an intraperitoneal injection of $12 \mathrm{~g} / \mathrm{l}$ Avertin at a dose of $240 \mathrm{mg} / \mathrm{kg}$ body weight four weeks after initial injection of MLD-STZ or citrate-citric acid buffer. A 2-mm disc of filter paper saturated with $1 \mathrm{~N} \mathrm{NaOH}$ was placed onto the left cornea of each mouse for $40 \mathrm{sec}$, followed by rinsing extensively with $10 \mathrm{ml}$ phosphate-buffered saline (PBS). The corneal epithelia were removed using a corneal knife in a rotary motion parallel to the limbus by gently scraping over the corneal surface without injuring the underlying corneal stroma, as previously described (12). Erythromycin ophthalmic ointment was instilled immediately following epithelial denudation. At the indicated time intervals (days 2 and 4 after alkali injury), mice were sacrificed with an intraperitoneal injection of sodium pentobarbitone at a dose of $300 \mathrm{mg} / \mathrm{kg}$ body weight (Virbac, Carindale, QLD, Australia) and the corneas were removed from the experimental eyes. The corneas were placed immediately into RNAlate (Qiagen GmbH, Hilden, Germany) and stored at $-86^{\circ} \mathrm{C}$ until total RNA extraction. In another series of experiments, the mice were sacrificed with an intraperitoneal injection of sodium pentobarbitone at a dose of $300 \mathrm{mg} / \mathrm{kg}$ body weight and the corneas were immediately removed from the alkali-treated eyes for measurement of CrNV. Each experiment was repeated at least three times.

Biomicroscopic examination of $\mathrm{CrNV}$. Eyes from aforementioned BALB/c mice were examined under a surgical microsystem (MZ16; Leica Microsystems GmbH, Wetzlar, Germany) 14 days after alkali injury, and prior to sacrifice and removal of corneas. In brief, while the mice were under anesthesia with an intraperitoneal injection of Avertin $(240 \mathrm{mg} / \mathrm{kg}$ body weight), photographs of the corneas were captured using a digital camera (Nikon Corporation, Tokyo, Japan) linked to an operating microscope. Microscopic assessment was performed by two independent observers with no prior knowledge of the experimental procedures.

Corneal whole mounts and enumeration of CrNV. Corneal whole mount staining with CD31 was performed and blood vessels in the corneas of the aforementioned BALB/c mice were measured according to a previous study (7). The mice were sacrificed with an intraperitoneal injection of sodium 
Table I. Sequences of the primers used for reverse transcription-polymerase chain reaction.

\begin{tabular}{|c|c|c|c|c|}
\hline Primers & Sequence $\left(5^{\prime}-3^{\prime}\right)$ & Product size (bp) & Annealing temperature $\left({ }^{\circ} \mathrm{C}\right)$ & PCR cycles \\
\hline VEGF & & 105 & 60 & 40 \\
\hline $\mathrm{F}$ & AGCTTCCTACAGCACAGCAG & & & \\
\hline $\mathrm{R}$ & GCGCTTTCGTTTTTGACCCT & & & \\
\hline HIF-1 $\alpha$ & & 198 & 60 & 40 \\
\hline $\mathrm{F}$ & TGCCACTTCCCCACAATGTGAG & & & \\
\hline $\mathrm{R}$ & CCATGTCGCCGTCATCTGTTAGCA & & & \\
\hline CCL-2 & & 100 & 60 & 40 \\
\hline $\mathrm{F}$ & GGTCCCTGTCATGCTTCTGGGC & & & \\
\hline $\mathrm{R}$ & GCAGCAGGTGAGTGGGGCG & & & \\
\hline CXCL-2 & & 130 & 60 & 40 \\
\hline $\mathrm{F}$ & TGCTGCTGGCCACCAACCAC & & & \\
\hline $\mathrm{R}$ & GGTCCTGGGGGCGTCACACT & & & \\
\hline CCL-3 & & 100 & 60 & 40 \\
\hline $\mathrm{F}$ & AGCTGACACCCCGACTGCCT & & & \\
\hline $\mathrm{R}$ & TGGCTGGGAGCAAAGGCTGC & & & \\
\hline SDF- $1 \alpha$ & & 101 & 60 & 40 \\
\hline F & CCAAGGTCGTCGCCGTGCTG & & & \\
\hline $\mathrm{R}$ & CTCGAAGAACCGGCAGGGGC & & & \\
\hline TSP-1 & & 197 & 60 & 40 \\
\hline $\mathrm{F}$ & GGTCGGCCTGCACTGTCACC & & & \\
\hline $\mathrm{R}$ & GGGGAAGCTGCTGCACTGGG & & & \\
\hline MMP-2 & & 100 & 60 & 40 \\
\hline $\mathrm{F}$ & AACGGTCGGGAATACAGCAG & & & \\
\hline $\mathrm{R}$ & GTAAACAAGGCTTCATGGGGG & & & \\
\hline MMP-9 & & 122 & 60 & 40 \\
\hline $\mathrm{F}$ & AAACCTCCAACCTCACGGAC & & & \\
\hline $\mathrm{R}$ & CTGAAGCATCAGCAAAGCCG & & & \\
\hline GAPDH & & 111 & 60 & 40 \\
\hline $\mathrm{F}$ & TTCACCACCATGGAGAAGGC & & & \\
\hline $\mathrm{R}$ & CTCGTGGTTCACACCCATCA & & & \\
\hline
\end{tabular}

All primers used were purchased from Genescript (Nanjing, China). The amplification was performed on iCycler iQ ${ }^{\mathrm{TM}}$ Multi-Color Real Time PCR Detection System (170-8740, Bio-Rad Laboratories, Inc., Hercules, CA, USA). F, forward primer; R, reverse primer; PCR, Polymerase Chain Reaction; VEGF, vascular endothelial growth factor; HIF, hypoxia inducible factor; CC, Chemokine (C-C motif) ligand; CXCL, C-X-C motif chemokine ligand; SDF, stromal cell-derived factor; TSP, Thrombospondin; MMP, matrix metalloproteinase; GAPDH, glyceraldehyde 3-phosphate dehydrogenase.

pentobarbitone at a dose of $300 \mathrm{mg} / \mathrm{kg}$ body weight and the corneas were rapidly removed from the alkali-treated eyes; Three or four relaxing radial incisions of each cornea were made. The corneal flat mounts were rinsed in PBS, fixed in acetone, and rinsed in PBS. The mounts were then blocked in $10 \%$ normal donkey serum (cat. no. 36116ES03; Shanghai Yeasen Biotechnology Co., Ltd., Shanghai, China), stained with rat anti-mouse CD31 (1:150; BD Biosciences) at $4^{\circ} \mathrm{C}$ overnight, and washed in PBS. Subsequently, the corneas were incubated with Alexa Fluor 488 donkey anti-rat IgG (1:100; Invitrogen; Thermo Fisher Scientific, Inc.) for $1 \mathrm{~h}$ at room temperature in the dark. Digital photographs of the flat mounts were captured and the area stained by CD31 was measured morphometrically using NIH Image software (National Institutes of Health, Bethesda, MD, USA). The total area of neovascularization was normalized to the total corneal area, and the percentage of the cornea covered by vessels was calculated.

Laser-induced ChNV. Laser treatment was performed on each C57BL/6 mouse retina as described previously (19). Specific pathogen-free nine-week-old C57BL/6 mice were anesthetized with an intraperitoneal injection of $12 \mathrm{~g} / \mathrm{l}$ Avertin at a dose of $240 \mathrm{mg} / \mathrm{kg}$ body weight and the pupils were dilated with a single drop of $1 \%$ tropicamide four weeks after initial injection of MLD-STZ or citrate-citric acid buffer. Krypton red laser photocoagulation (50 $\mu \mathrm{m}$ spot size, $0.05 \mathrm{sec}$ duration, $250 \mathrm{~mW}$ ) was used to generate three laser spots in the eye surrounding the optic nerve, using a hand-held coverslip as a contact lens. A bubble forming at a laser spot indicated rupture of Bruch's membrane. The laser spots were evaluated 


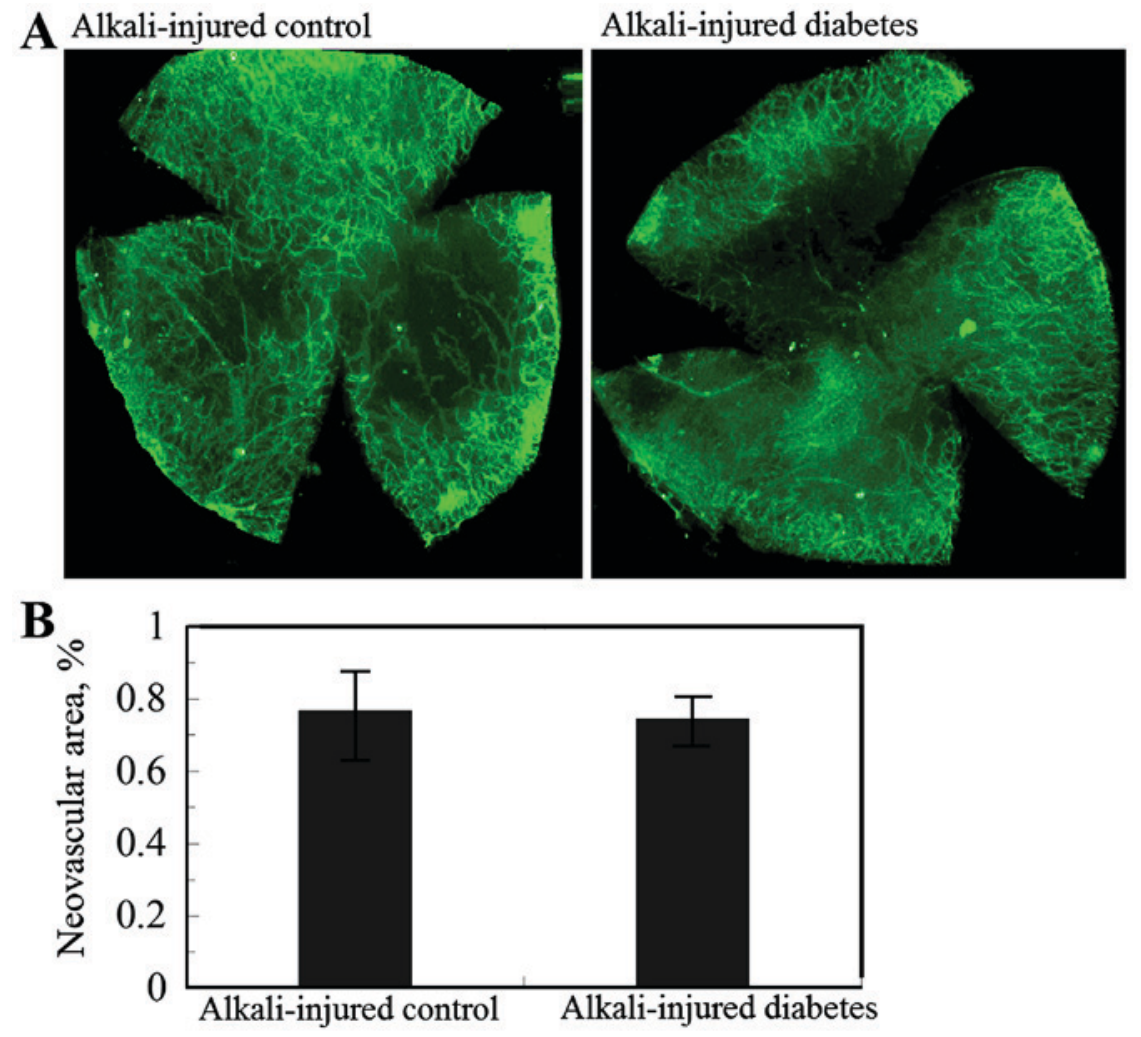

Figure 1. Effect of STZ-induced diabetes on alkali induced CrNV. (A) Representative CrNV assessed by CD31 corneal whole mount staining. Original magnification, x25. (B) The relative neovascular areas were compared between the alkali-injured diabetic and alkali-injured control mice. All values represent mean \pm standard error of the mean ( $\mathrm{n}=5$ animals). STZ, streptozocin; CrNV, corneal neovascularization; $\mathrm{CD}$, cluster of differentiation.

for the presence of ChNV on day 14 after laser treatment using fundus fluorescein angiography and CD31 choroidal whole mount staining (as described below). Laser coagulation was performed only in the left eye of each mouse, with the right eye serving as the control. At the indicated time intervals (days 2 and 4 after laser treatment), mice were sacrificed with an intraperitoneal injection of sodium pentobarbitone at a dose of $300 \mathrm{mg} / \mathrm{kg}$ body weight and choroids were removed from the experimental eyes. The choroids were placed immediately into RNAlate and stored at $-86^{\circ} \mathrm{C}$ until total RNA extraction. In another series of experiments of choroidal whole mount staining on day 14 after laser treatment and after fluorescein angiography, the mice were sacrificed with an intraperitoneal injection of sodium pentobarbitone at a dose of $300 \mathrm{mg} / \mathrm{kg}$ body weight and the choroids were immediately removed from the laser-treated eyes for measurement of ChNV. Each experiment was repeated at least three times.

Fluorescein angiography. Fluorescein angiography was conducted 14 days after laser treatment. Briefly, the C57BL/6 mice were anesthetized with an intraperitoneal injection of $12 \mathrm{~g} / \mathrm{l}$ Avertin at a dose of $240 \mathrm{mg} / \mathrm{kg}$ body weight. Pupils from the aforementioned C57BL/6 mice were dilated using $2.5 \%$ phenylephrine hydrochloride and $1 \%$ tropicamide eye drops. Subsequently, $10 \%$ fluorescein sodium chloride was injected intraperitoneally into the anesthetized mice. After 180-200 sec, fundus photos were captured using an angiography camera (KOWA RC-XV3; Kowa Company, Ltd., Osaka, Japan); Two experienced individuals who were blinded to the study processed and scored the images. Scores were determined as previously described: 0 , no staining; 1 , slight leakage; 2a, moderate leakage; and 2b, heavy leakage (19). Images were standardized for the process. The area covered with ChNV was determined using Image J software (available at http://rsb.info.nih.gov/ij/index.html), version 1.62 (National Institutes of Health).

Choroidal whole mounts and morphological determination of neovascularization. The choroids from aforementioned C57BL/6 mice that were excised for ChNV assays on day 14 after laser treatment and fluorescein angiography, were rinsed in PBS and fixed in acetone for $20 \mathrm{~min}$. After washing and blocking with $2 \%$ bovine serum albumin (cat. no. 11021029; Gibco; Thermo Fisher Scientific, Inc.) in PBS for $1 \mathrm{~h}$, the choroids were stained overnight at $4^{\circ} \mathrm{C}$ with rat anti-mouse CD31 antibody (BD Biosciences). The choroids were rinsed and then stained with an Alexa Fluor ${ }^{\circledR}$ 488-conjugated secondary donkey anti-rat antibody (Invitrogen; Thermo Fisher Scientific, Inc.). The choroids were placed on slides, covered with fluorescent mounting medium (Dako; Agilent Technologies, Inc., Santa Clara, CA, USA) and stored at $4^{\circ} \mathrm{C}$ in the dark. The stained choroidal whole mounts were analyzed using a fluorescence microscope at an excitation wavelength of 495 nm (MZ16; Leica Microsystems GmbH). Each whole mount image was captured at x25 magnification. The area covered with neovascular tubes was determined using Image J software.

RNA isolation and reverse transcription-quantitative polymerase chain reaction ( $R T-q P C R)$. Total RNA was extracted 

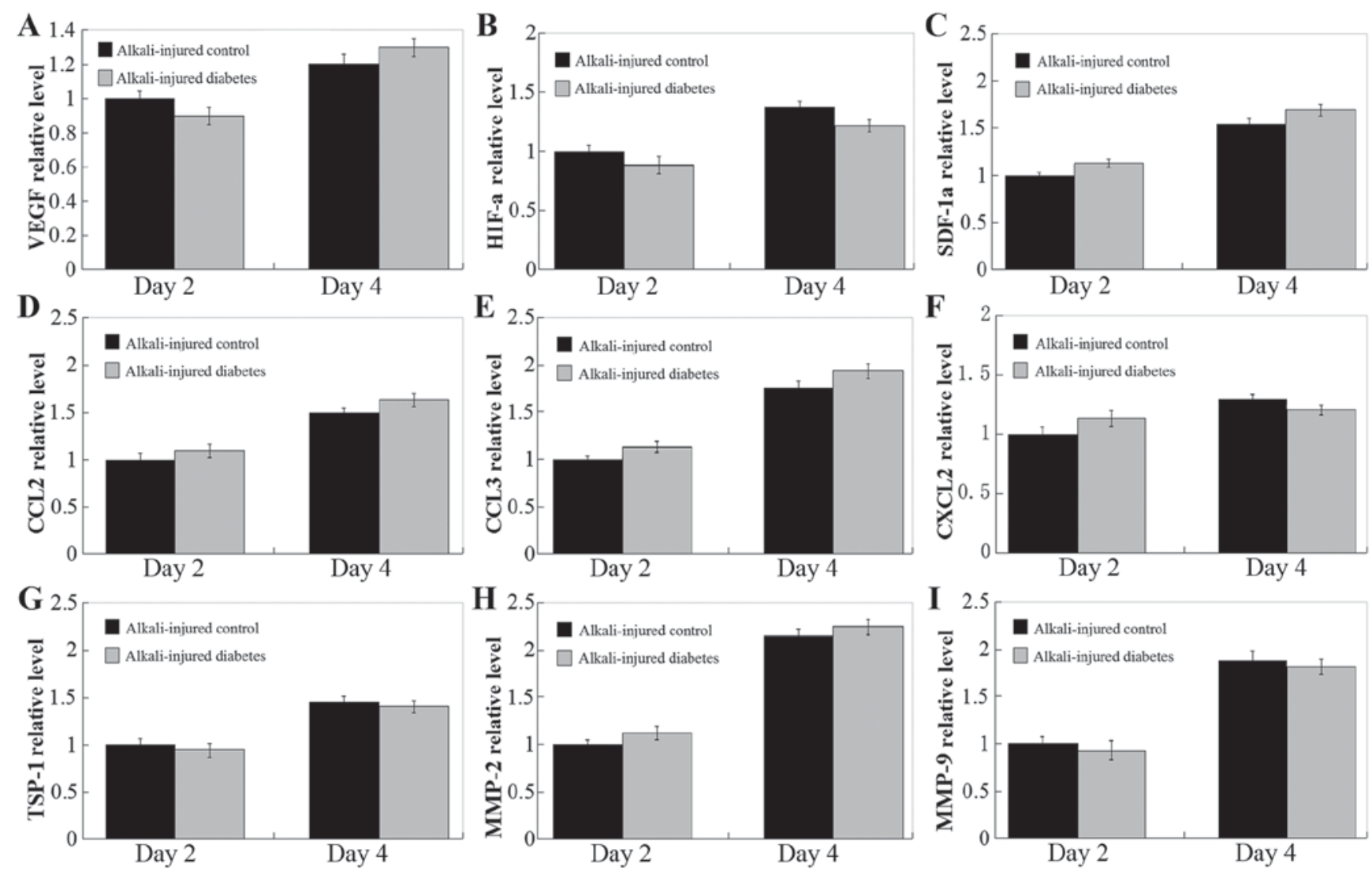

Figure 2. RT-qPCR analysis of relative intracorneal target gene expression levels in alkali-injured control and alkali-injured diabetic mice (STZ-induced). Ratios of (A) VEGF, (B) HIF-1 $\alpha$, (C) SDF-1 $\alpha$, (D) CCL2, (E) CCL3, (F) CXCL-2, (G) TSP-1, (H) MMP-2 and (I) MMP-9 to GAPDH of the alkali-injured control mice (black bars) and diabetic mice (grey bars) were determined by RT-qPCR at the indicated time intervals after alkali injury. Values represent mean \pm standard error of the mean ( $\mathrm{n}=5$ animals). STZ, streptozocin; VEGF, vascular endothelial growth factor; CC, Chemokine (C-C motif) ligand; HIF, hypoxia inducible factor; SDF, stromal cell-derived factor; CXCL, C-X-C motif chemokine ligand; TSP, Thrombospondin; MMP, matrix metalloproteinase; GAPDH, glyceraldehyde 3-phosphate dehydrogenase; RT-qPCR, reverse transcription-quantitative polymerase chain reaction.

from the corneas of BALB/c mice or choroids of C57BL/6 mice after alkali treatment on corneas or laser treatment on choroids using an RNeasy Mini Kit (Qiagen $\mathrm{GmbH}$ ). The resultant RNA preparations were further treated with RNase-free DNase (Thermo Fisher Scientific, Inc.) to remove genomic DNA. The PCR solution contained $2 \mu \mathrm{l}$ cDNA, the specific primer set $(0.2 \mu \mathrm{M}$ final concentration), and $12.5 \mu \mathrm{l}$ SYBR $^{\circledR}$ Premix Ex Taq ${ }^{\mathrm{TM}}$ (SYBR $^{\circledR}$ Premix Ex Taq ${ }^{\mathrm{TM}}$ Perfect Real Time PCR Kit; Takara Bio Inc., Kusatsu, Japan) in a final volume of $25 \mu \mathrm{l}$. The sequences of the PCR primer pairs are listed in Table I. Quantitative PCR was performed using an iCycler $\mathrm{iQ}^{\mathrm{TM}}$ Multi-Color Real Time PCR Detection System (170-8740; Bio-Rad Laboratories, Hercules, CA, USA). The PCR parameters involved initial denaturation at $95^{\circ} \mathrm{C}$ for $1 \mathrm{~min}$, followed by 40 cycles of $95^{\circ} \mathrm{C}$ for $5 \mathrm{sec}$ and $60^{\circ} \mathrm{C}$ for $30 \mathrm{sec}$. The relative gene expression levels were calculated using the $2^{-\Delta \Delta C q}$ method (20), where $\mathrm{Ct}$ represents the threshold cycle, and GAPDH was used as a reference gene.

Western blot analysis. Choroidal lysates were prepared from samples of the C57BL/6 mice taken at the indicated time interval after laser injury. Protein samples, quantified using NanoDrop 2000 UV-Vis Spectrophotometer (30 $\mu \mathrm{g} / \mathrm{each}$ lane; Thermo Fisher Scientific, Inc.) were dissolved in Laemmli buffer (cat. no. 1610737; Bio-Rad Laboratories, Inc., Hercules,
CA, USA), boiled for 3-4 min, and centrifuged at $4^{\circ} \mathrm{C}$ for $2 \mathrm{~min}$ at $20,000 \mathrm{x}$ g to remove insoluble materials. A total of $30 \mu \mathrm{g}$ protein per lane was separated by SDS-PAGE (12\%) and transferred to $0.2 \mu \mathrm{m}$ nitrocellulose membranes. The blocked membranes were probed overnight $\left(4^{\circ} \mathrm{C}\right)$ with goat anti-VEGF (1:200; sc-152-G; Santa Cruz Biotechnology, Inc.), goat anti-HIF-1 $\alpha$ (1:200; sc-12542Y-15; Santa Cruz Biotechnology, Inc.), goat anti-SDF-1 $\alpha$ (1:200; sc-7427; Santa Cruz Biotechnology, Inc.), goat anti-CCL3 (1:1,000; AB-450-NA; R\&D Systems) or goat anti-GAPDH antibodies (1:200; sc-48166; Santa Cruz Biotechnology). The membranes were then incubated at RT for $1 \mathrm{~h}$ with a horseradish peroxidase-conjugated rabbit anti-goat secondary antibody (1:5,000; 5160-2504; R\&D Systems), and immunoreactive bands were visualized using ECL reagent (Advansta, Menlo Park, CA, USA). The intensities of the protein bands were quantified and normalized to GAPDH using Image J Software version 2.1.4.7 (National Institutes of Health, Bethesda, MD, USA).

Flow cytometry of intrachoroidally infiltrating progenitor cells and macrophages. Mononuclear cells were isolated from choroids of C57BL/6 mice according to a previously described procedure, with some modifications $(10,11)$. Briefly, at day 4 after the laser injury, choroids were removed, teased away with scissors, and incubated at $37^{\circ} \mathrm{C}$ for $30 \mathrm{~min}$ with constant shaking in the presence of $0.5 \mathrm{mg} / \mathrm{ml}$ collagenase type D 
A Laser-injured control

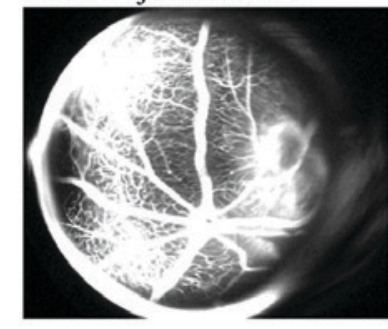

C Laser-injured control

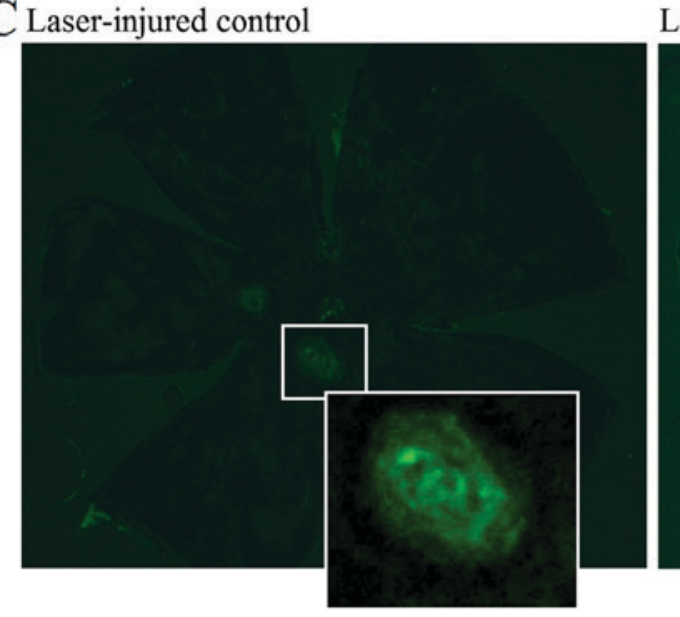

B

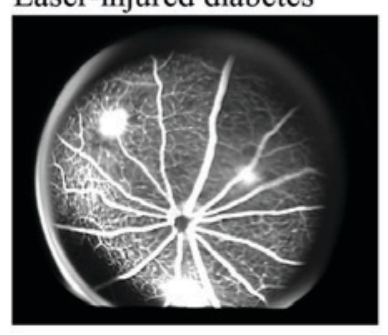

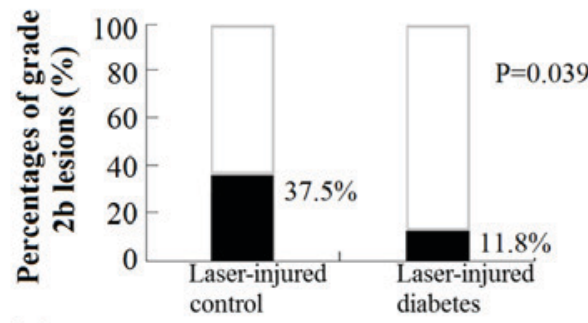

Laser-injured diabetes

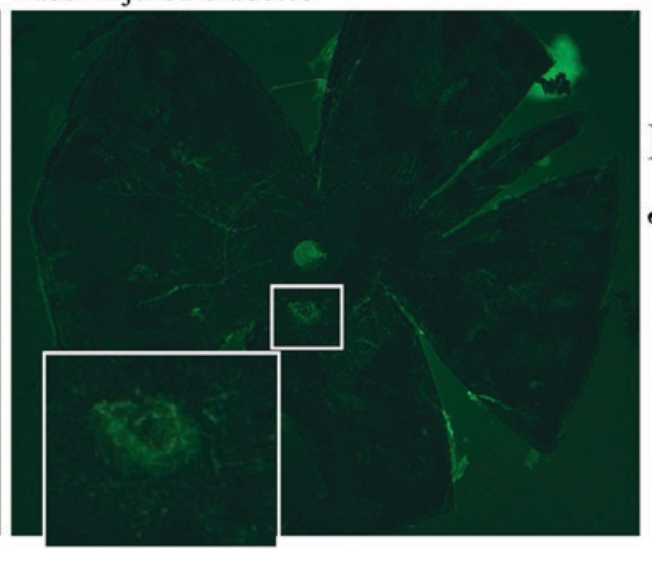

D

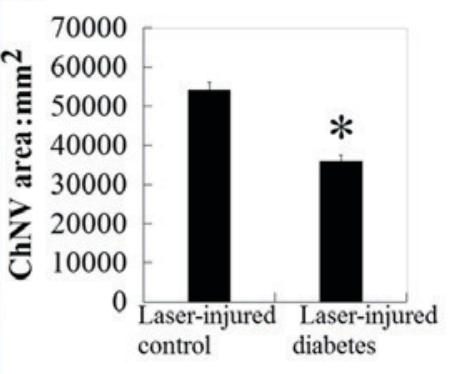

Figure 3. Effect of STZ-induced diabetes on laser-induced ChNV. (A) Representative fundus angiographic leakage of the laser-injured diabetic and laser-injured control mice two weeks after laser injury. (B) Percentages of grade $2 b$ lesions were statistically evaluated and analyzed by $\chi^{2}$ test. (C) Representative ChNVs assessed by choroidal whole mount cluster of differentiation 31 staining of the laser-injured control and laser-injured diabetic mice. Original magnification, $\mathrm{x} 25$ and $\mathrm{x} 100$. (D) ChNV areas were statistically evaluated and compared by Student's t-test. Each value represents mean \pm standard error of the mean (n=5 animals). ${ }^{*} \mathrm{P}<0.05$ vs. laser-injured control mice. STZ, streptozocin; ChNV, choroidal neovascularization.

(Roche Diagnostics, Mannheim, Germany). Cell suspensions were then passed over a nylon filter with a pore size of $100 \mu \mathrm{m}$. The resultant cells were stained with FITC-labeled rat anti-mouse F4/80 monoclonal antibody (1:10) or goat anti-c-Kit antibody (1:100) at $4^{\circ} \mathrm{C}$ for $25 \mathrm{~min}$, then washed with PBS and centrifuged at $1,500 \mathrm{x} \mathrm{g}$ at $4^{\circ} \mathrm{C}$ for $5 \mathrm{~min}$. Subsequently, cells were further stained with PE-conjugated rabbit anti-goat $\mathrm{IgG}$ monoclonal antibody $(1: 100)$ at $4^{\circ} \mathrm{C}$ for $25 \mathrm{~min}$, then washed with PBS and centrifuged at $1,500 \mathrm{xg}$ at $4^{\circ} \mathrm{C}$ for $5 \mathrm{~min}$. Samples stained with non-immunized goat IgG (Sigma-Aldrich; Merck $\mathrm{KGaA}$ ) were used as the isotype control. Fluorescence intensities were determined using a Beckman Coulter Cytomics FC 500 flow cytometer (Beckman Coulter, Inc., Brea, CA, USA) and the data were analyzed using FlowJo version 7.6.1 (FlowJo LLC, Ashland, OR, USA).

Statistical analysis. All experimental data were expressed as the mean \pm standard error of the mean and analyzed with statistical software SPSS version 18.0 (SPSS, Inc., Chicago, IL, USA). All experiments were repeated at least three times. Data of gene expression of intracorneal and intrachoroidal angiogenic factors were statistically analyzed using one-way analysis of variance followed by the post hoc Tukey's test. Data of $\mathrm{CrNV}$ areas, $\mathrm{ChNV}$ areas, protein expression of intrachoroidal angiogenic factors and $\mathrm{C}-\mathrm{Kit}^{+}$and $\mathrm{F} 4 / 80^{+}$cell numbers were statistically analyzed using the unpaired Student's t-test. Count data for grade $2 b$ lesions were compared using the $\chi^{2}$ test. $\mathrm{P}<0.05$ was considered to indicate a statistically significant difference.

\section{Results}

Effects of diabetes on alkali-induced CrNV. CrNV was macroscopically evident in mice two weeks after the alkali injury, which was consistent with the results of previous studies (10-13). Macroscopic inspection revealed that the untreated corneas were avascular and that alkali injury markedly increased the vascular areas in corneas two weeks after injury (data not shown). However, immunofluorescent staining analysis using anti-CD31 antibodies demonstrated that there was no statistical difference in the size of the CD31-positive area between the alkali-injured normal and alkali-injured diabetic mice $(\mathrm{P}>0.05)$ (Fig. 1). These results indicated that STZ-induced diabetes has no significant effect on the development of alkali-induced CrNV.

Intracorneal angiogenic factor expression in STZ-induced diabetic mice after alkali injury. The balance between angiogenic and anti-angiogenic factors determines the occurrence of angiogenic processes. Therefore, the mRNA expression of angiogenic factors in corneas at days 2 and 4 after alkali injury was determined $(10,11)$. Alkali injury enhanced the mRNA expression of various angiogenesis-associated factors, including VEGF, HIF-1 $\alpha$, SDF-1 $\alpha$, CCL2, CCL3, and chemokine (C-X-C motif) ligand (CXCL) 2 (data not shown). However, there were no statistically significant differences in the intracorneal mRNA expression levels of these factors and other factors, such as thrombospondin (TSP)-1, matrix metallopeptidase (MMP)-2 or MMP-9, between the alkali-injured 

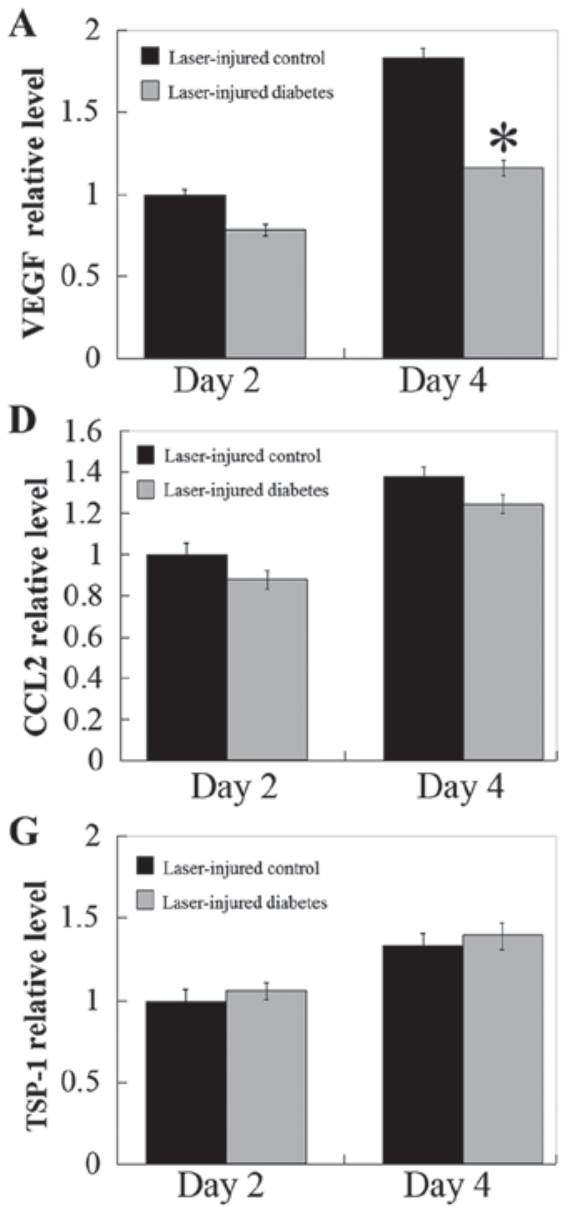

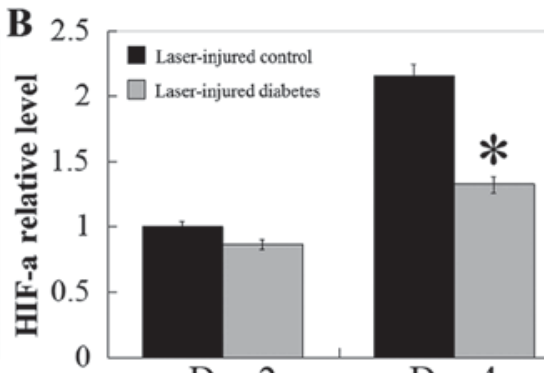

Day 2

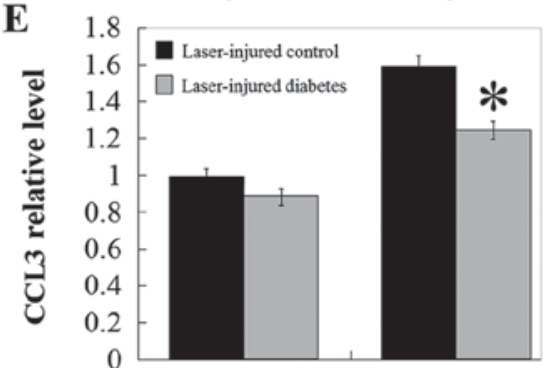

Day 2

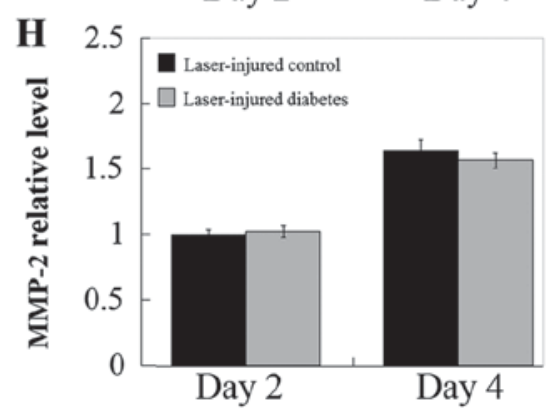



Day 2

Day 4

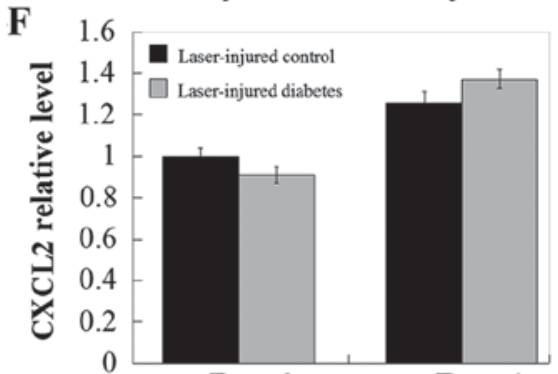

Day 2

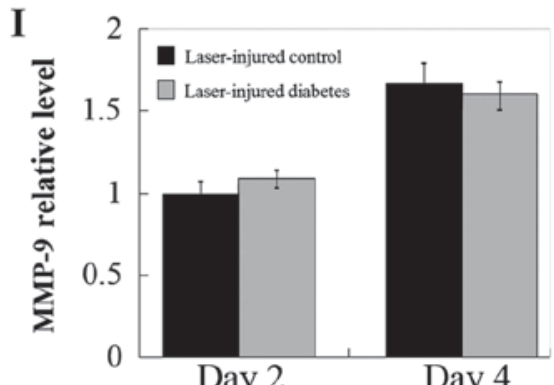

Figure 4. Gene expression of intrachoroidal angiogenic factors. Ratios of (A) VEGF, (B) HIF-1 $\alpha$, (C) SDF-1 $\alpha$, (D) CCL-2, (E) CCL3, (F) CXCL2, (G) TSP-1, (H) MMP-2 and (I) MMP-9 to GAPDH of the laser-injured control mice (black bars) and laser-injured diabetic mice (grey bars) were determined by reverse transcription-quantitative polymerase chain reaction at the indicated time intervals after laser injury. Each value represents mean \pm standard error of the mean ( $\mathrm{n}=5$ animals). ${ }^{*} \mathrm{P}<0.05$ vs. laser-injured control mice. VEGF, vascular endothelial growth factor; HIF, hypoxia inducible factor; SDF, stromal cell-derived factor; CC, Chemokine (C-C motif) ligand; CXCL, C-X-C motif chemokine ligand; TSP, Thrombospondin; MMP, matrix metalloproteinase; GAPDH, glyceraldehyde 3-phosphate dehydrogenase.

diabetic and alkali-injured control mice at days 2 and 4 after alkali injury ( $\mathrm{P}>0.05$; Fig. 2).

Diabetic mice exhibit impaired angiographic leakage from $C h N V$ lesions. Fluorescein angiography revealed that the laser-induced ChNV size was significantly decreased in the laser-injured diabetic mice compared with the laser-injured control mice. On day 14, significant pathological leakage (grade $2 \mathrm{~b}$ lesions) was observed in $37.5 \%$ of the lesions in the laser-injured control mice, but only $11.8 \%$ of the lesions in the laser-injured diabetic mice. The difference in the percentages of grade $2 b$ lesions between the laser-injured diabetic and laser-injured control mice was statistically significant $\left(\chi^{2}\right.$ test, $\mathrm{P}=0.039$; Fig. $3 \mathrm{~A}$ and $\mathrm{B}$ ).

Diabetic mice exhibit impaired laser-induced ChNV. The mean size of the laser-induced $\mathrm{ChNV}$, measured in flat mounted choroids, was smaller in the eyes of the laser-injured diabetic mice on day 14 after laser application compared with laser-injured control mice (Fig. 3C). The size of the ChNV was $53732.81 \pm 5755.5 \mu \mathrm{m}^{2}$ in the laser-injured control mice and $33883.89 \pm 5344.60 \mu \mathrm{m}^{2}$ in the laser-injured diabetic mice (68.1\% of control). The laser-injured diabetic mice exhibited a significant decrease in $\mathrm{ChNV}$ size compared to with the laser-injured control mice ( $\mathrm{P}=0.031$; Fig. 3D).

Diabetic mice exhibit reduced intrachoroidal VEGF, HIF-1 $\alpha$, $C C L 3$, and SDF-1 $\alpha$ expression after laser injury. In order to identify the mechanism of STZ-induced diabetes on impaired laser-induced $\mathrm{ChNV}$, the intrachoroidal angiogenic cytokine and chemokine expression levels in the laser-injured diabetic and laser-injured control mice at days 2 and 4 after laser injury were determined using RT-qPCR. The results indicated that the expression of VEGF, HIF-1 $\alpha$, SDF-1 $\alpha$ and CCL3 were markedly reduced in the choroids of the laser-injured diabetic mice when compared with the laser-injured control mice at day 4 following laser injury $(\mathrm{P}<0.05$; Fig. 4$)$. Consistently, the protein expression levels of intrachoroidal VEGF, HIF-1 $\alpha$, SDF-1 $\alpha$ and CCL3 were also reduced in the laser-injured diabetic mice compared with the laser-injured control mice at day 4 ( $\mathrm{P}<0.05$; Fig. 5). These observations demonstrated that diabetes downregulated angiogenic molecule expression and then reduced laser-induced $\mathrm{ChNV}$.

Diabetic mice exhibit impaired progenitor cell infiltration in wounded choroids following laser injury. In the present study, 
A

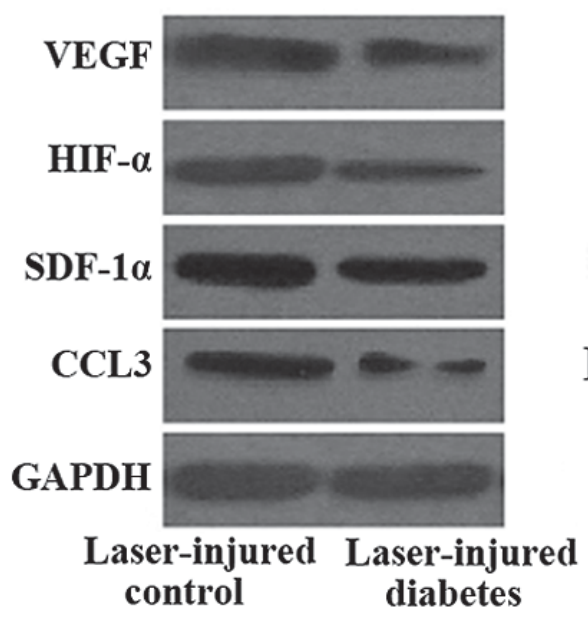

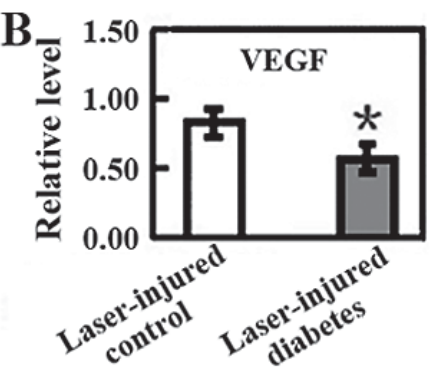
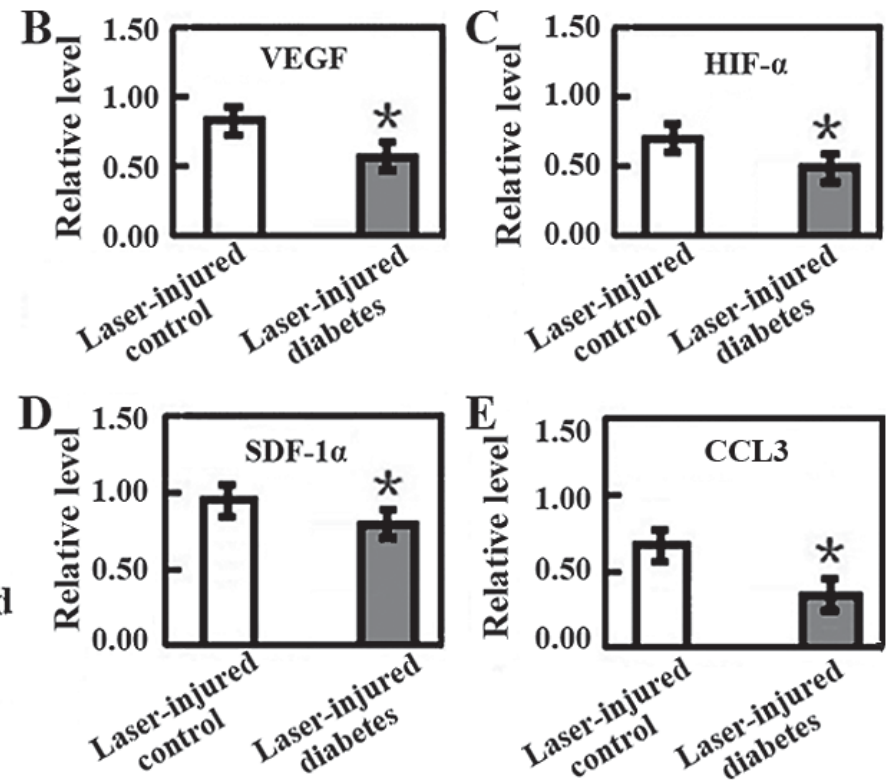

Figure 5. Protein expression levels of intrachoroidal angiogenic factors. Protein extracts were obtained and subjected to western blot analysis. (A) Representative results from three independent experiments are shown here. Ratios of (B) VEGF, (C) HIF-1 $\alpha$, (D) SDF-1 $\alpha$ and (E) CCL3 to GAPDH of the laser-injured control mice (open bars) and laser-injured diabetic mice (grey bars) were determined by western blotting at day 4 after laser injury. Each value represents mean \pm standard error of the mean ( $\mathrm{n}=5$ animals). ${ }^{*} \mathrm{P}<0.05$ vs. laser-injured control mice. VEGF, vascular endothelial growth factor; HIF, hypoxia inducible factor; SDF, stromal cell-derived factor; CC, Chemokine (C-C motif) ligand; GAPDH, glyceraldehyde 3-phosphate dehydrogenase.

flow cytometric analyses of intrachoroidally infiltrating cells demonstrated that the levels of $\mathrm{c}-\mathrm{Kit}^{+}$cell infiltration were markedly reduced in the laser-injured diabetic mice compared with the laser-injured control mice after laser injury $(\mathrm{P}<0.05$; Fig. 6). The levels of $\mathrm{F} 4 / 80^{+}$macrophage intrachoroidal infiltration were lower in the laser-injured diabetic mice compared with the laser-injured control mice, but there was no statistically significant difference between the two groups $(\mathrm{P}>0.05$; Fig. 6). These observations indicated that diabetes reduced laser-induced infiltration of progenitor cells rather than macrophages.

\section{Discussion}

CrNV, which frequently leads to impaired vision, can result from a number of causes, including corneal infections, misuse of contact lenses, chemical burns and inflammation (7-9). AMD and DR are major causes of low vision and blindness throughout the world. The influence of lifestyle, as well as vitamin and antioxidant supplementation, in the development and prevention of AMD is well known (21-24). However, to the best of our knowledge, the effects of diabetes in CrNV and AMD remain unknown.

Diabetes can cause blood vessel and microvascular abnormalities, and multiple organ systemic complications in the cardiovascular system, urinary system and eye lesions (25). Complications leading to local tissue ischemia, hypoxia, and microcirculatory disturbances are caused by a variety of mechanisms, including polyol pathway metabolism (26), abnormally activated protein kinase $C$ pathways (27), increased oxidative stress (28) and the accumulation of advanced glycation end-products (AGEs) (29). In the wound-healing process, diabetes can inhibit angiogenesis and thus cause delayed wound healing (30).
Alkali injury-induced CrNV involves inflammatory neovascularization caused by burn lesions. In the early phase of alkali-induced CrNV, neutrophils, macrophages, and other inflammatory cells infiltrate the corneal stroma and release large amounts of inflammatory cytokines. da Costa Pinto and Malucelli (31) and Zagon et al (32) suggested that STZ-induced diabetic rats exhibit reduced alkali injury-induced CrNV compared to control rats, but failed to show a significant difference in VEGF or bFGF expression between the two groups. Waltenberger et al and Tchaikovski et al found that monocytes obtained from diabetic patients exhibit decreased VEGF-A-induced chemotaxis in vitro, and proposed the putative concept of 'VEGF resistance', involving VEGF-A/VEGF receptor-1-mediated chemotaxis in monocytes from patients with diabetes $(33,34)$.

In the present study, a statistically significant difference in the CrNV between alkali-injured diabetic and alkali-injured control mice was not identified. There are several observations supporting our conclusion. First, diabetic animals are usually used in the study of limb ischemia or the skin wound-healing process. It is accepted that diabetes can affect wound healing by inhibiting angiogenesis. However, in corneas, the micro-environment is immune specific, which may cause different effects of diabetes on angiogenesis. Second, rats are widely used as STZ-induced diabetic animals, while in the present study, BALB/c mice were used. There is a different response of CrNV development to circulatory high-glucose stimulation between different species. Third, diabetic complications can be divided into acute and chronic pathologies. The majority of diabetic vascular anomalies occur gradually. AGEs may occur through a chronic pathological process. There is the possibility that a different effect on CrNV may gradually appear with a long duration of diabetes. The results of the present study suggested that in the early stages of the disease, diabetes has 
A

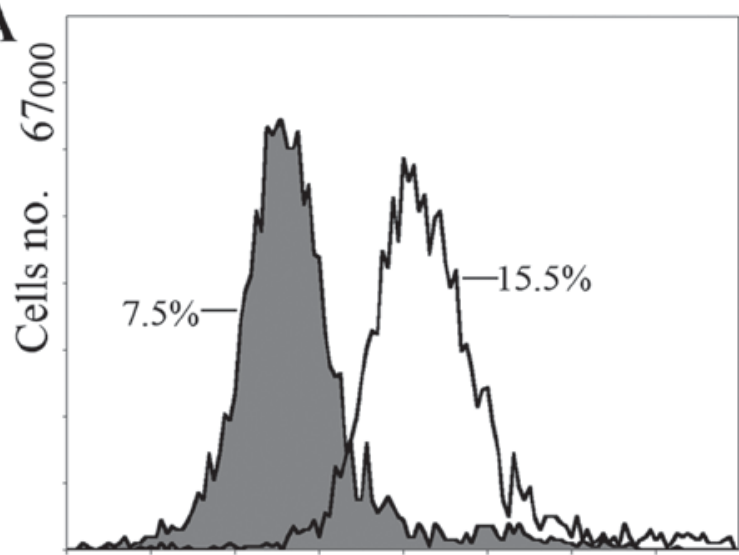

PE label

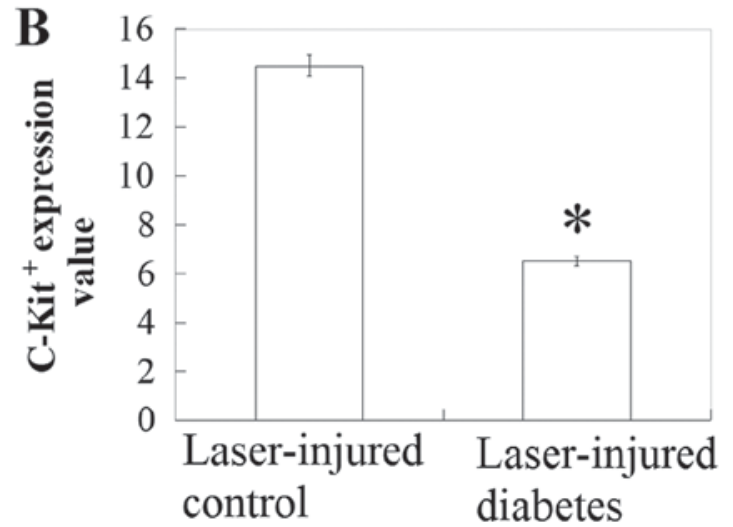

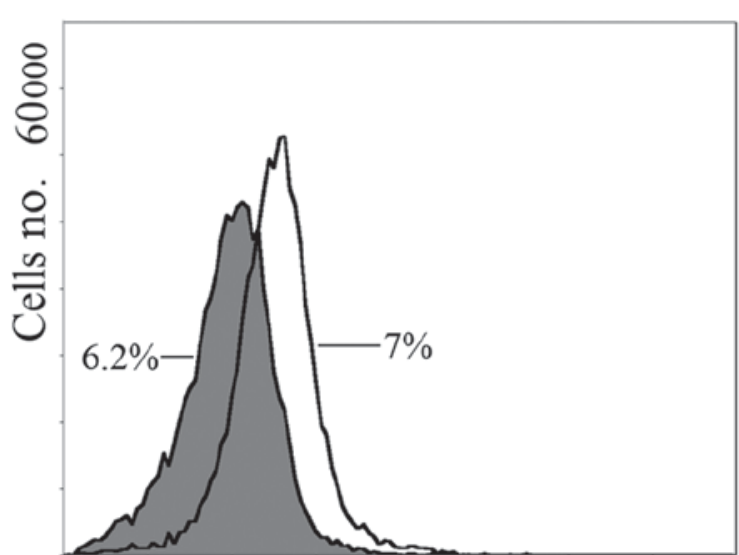

FITC label

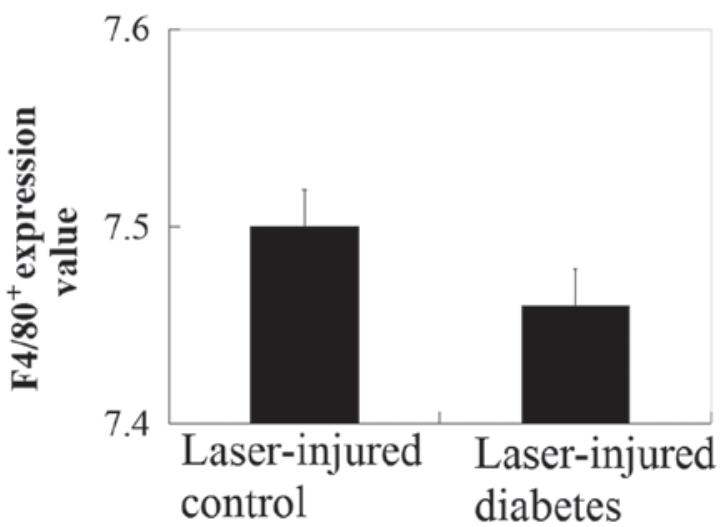

Figure 6. C-Kit ${ }^{+}$and $\mathrm{F} 4 / 80^{+}$cell numbers in choroid following laser photocoagulation. (A) Open heavy-lined histogram indicates the value from the laser-injured control mice and filled histogram indicates the value from the laser-injured diabetic mice. Representative results from three independent experiments are shown. (B) C-Kit (left plot) and $\mathrm{F} 4 / 80^{+}$(right plot) cell numbers were statistically determined. Each value represents the mean \pm standard error of the mean ( $\mathrm{n}=5$ animals). ${ }^{*} \mathrm{P}<0.05$ vs. laser-injured control mice.

no significant effect on alkali injury-induced $\mathrm{CrNV}$, as the blood glucose of the mice had already reached the diabetic level.

The neovascular form of AMD, ChNV, occurs in at least $0.6-0.7 \%$ of the population (35). Trauma, traction, degeneration, and inflammatory invasion destroy the normal structures of Bruch's membrane, leading to exposure of retinal pigmented epithelial cells, choroidal capillary endothelial cells, pericytes, and inflammatory cells to proinflammatory conditions, and thereby inducing the occurrence of ChNV. In this process, VEGF and platelet-derived growth factor (PDGF) are major contributing factors (36). ChNV maintenance depends on the balance of angiogenic and anti-angiogenic factors such as PEDF, angiostatin, and endostatin. RPE may secrete VEGF, monocyte chemoattractant protein 1, and IL-8, as well as other cytokines, in order to regulate monocyte and endothelial cell migration during ChNV formation (37-41).

Wound healing under hypoxic conditions induces increased expression of HIF- $1 \alpha$ and promotes VEGF secretion. The infiltration of SDF-1 $\alpha /$ CXCR4-mediated bone marrow-derived endothelial progenitor cells (BM EPC) into the wounded area can promote wound healing. It has been reported that diabetes caused by high blood glucose can inhibit BM EPC mobilization by reducing the SDF-1 $\alpha / C X C R 4$ signal (42). Gallagher et al (43) demonstrated that high glucose can block eNOS activation and reduce SDF-1 $\alpha$ expression, thereby causing reduced BM
EPC mobilization and delayed wound healing (43). During laser-induced $\mathrm{ChNV}$, a wound-healing process occurs after laser coagulation. Thus, it is logical that STZ-induced diabetic mice have impaired wound healing following laser injury.

The present study demonstrated that laser-induced ChNV was markedly reduced in the laser-injured diabetic mice compared with the laser-injured control mice. In order to eliminate the differences attributable to different experimental species, laser induced-ChNV was also detected in laser-injured diabetic (STZ-induced) BN (Brown Norway) rats and laser-injured control $\mathrm{BN}$ rats, and a similar result was obtained (data not shown). The data suggested that diabetes had a negative effect on $\mathrm{ChNV}$ development. Intrachoroidal angiogenic factor expression after laser injury was also examined and it was revealed that the enhancement of VEGF, HIF-1 $\alpha$, CCL3, and SDF-1 $\alpha$ expression levels was impaired in the laser-injured diabetic mice compared with the laser-injured control mice. Jiraritthamrong et al (44) and Cao et al (45) found that high glucose conditions suppressed the in vitro vessel-forming capacity of endothelial progenitor cells. Notably, the authors previously reported that $\mathrm{c}-\mathrm{Kit}^{+}$progenitor cells and $\mathrm{F} 4 / 80^{+}$ macrophages infiltrate the injured corneas, reaching their peak levels two to four days after alkali injury during experimental CrNV in wild type mice $(10,11)$. In the present study, c-Kit ${ }^{+}$ cell intrachoroidal infiltration was significantly impaired in the laser-injured diabetic mice. Thus, diabetes downregulated 
$\mathrm{ChNV}$, at least in part, through impaired c-Kit ${ }^{+}$progenitor endothelial cell infiltration and vessel formation. The results of the present study provide novel evidence that experimental ChNV development is associated with diabetes.

There are conflicting reports regarding the association between diabetes and AMD. Klein et al (46) and Song et al (47) found that the association between diabetes and early AMD or dry AMD was not obvious. However, an AMD prevalence survey of Korean participants over the age of 50 years revealed that in diabetic patients, the probability of early AMD is higher than that in the nondiabetic population (48). Another study of a European population suggested that there is a positive association of DM with neovascular AMD (49). As the incidence rates of both diabetic disease and AMD increase with age, whether diabetes and AMD have pathological connections requires further investigation. Moreover, the acute wound healing process after laser injury during experimental ChNV probably differs from that occurring naturally in the human AMD process. If this is correct, it is important to note the limitation of laser-induced experimental ChNV for use as an animal model of AMD.

In conclusion, the results of the present study demonstrated that diabetes is involved in the process of neovascularization in experimental laser-induced $\mathrm{ChNV}$ model. It was revealed that diabetes reduced $\mathrm{ChNV}$. Furthermore, the pro-angiogenic factors VEGF-A, HIF-1 $\alpha$, SDF-1 $\alpha$ and CCL3 were reduced in the laser-injured diabetic mice compared with the laser-injured control mice; the level of intrachoroidal c-Kit ${ }^{+}$progenitor cell infiltration was decreased in the laser-injured diabetic mice compared with the laser-injured control mice. Taken together, these findings suggested that diabetes reduced $\mathrm{ChNV}$ through downregulation of intrachoroidal progenitor cell infiltration and angiogenic factor expression.

\section{Acknowledgements}

Not applicable.

\section{Funding}

The present study was supported by the National Natural Science Foundation in China (grant nos. 81671641, 81200727, 31600736), Suzhou Municipal Natural Science Foundation (grant no. SYS201745), Jiangsu Provincial Medical Youth Talent (grant no. QNRC2016718), Jiangsu Provincial Medical Innovation Team (grant no. CXTDA2017039), Jiangsu Provincial Natural Science Foundation (grant no. BK20151208) and the Soochow Scholar Project of Soochow University (grant no. R5122001).

\section{Availability of data and materials}

All data generated or analyzed during this study are included in this published article.

\section{Authors' contributions}

GL and HW designed the study, led the experiments, prepared figures and wrote the manuscript. LC, QC and ZC analyzed the data and prepared the figures. $\mathrm{XZ}$ conceived and designed the study as well as drafted the manuscript. PL conceived, designed and coordinated the study as well as drafted the manuscript. All authors read and approved the final manuscript.

\section{Ethics approval and consent to participate}

All animal experiments followed the Guideline for the Care and Use of Laboratory Animals of the Chinese Medical Academy and were approved by the Soochow University Animal Care Committee (Suzhou, China), and were performed in accordance with the ARVO Statement for the Use of Animals in Ophthalmic and Vision Research.

\section{Patient consent for publication}

Not applicable.

\section{Competing interests}

The authors declare that they have no competing interests.

\section{References}

1. Wild S, Roglic G, Green A, Sicree R and King H: Global prevalence of diabetes: Estimates for 2000 and projections for 2030. Diabetes Care 27: 1047-1053, 2004.

2. Smith SC, Lamping DL and Maclaine GD: Measuring health-related quality of life in diabetic peripheral neuropathy: A systematic review. Diabetes Res Clin Pract 96: 261-270, 2012.

3. Laiteerapong N, Karter AJ, Liu JY, Moffet HH, Sudore R, Schillinger D, John PM and Huang ES: Correlates of quality of life in older adults with diabetes: The diabetes \& aging study. Diabetes Care 34: 1749-1753, 2011

4. Keymel S, Heinen Y, Balzer J, Rassaf T, Kelm M, Lauer T and Heiss C: Characterization of macro-and microvascular function and structure in patients with type 2 diabetes mellitus. Am J Cardiovasc Dis 1: 68-75, 2011.

5. Leiva A, Pardo F, Ramírez MA, Farías M, Casanello P and Sobrevia L: Fetoplacental vascular endothelial dysfunction as an early phenomenon in the programming of human adult diseases in subjects born from gestational diabetes mellitus or obesity in pregnancy. Exp Diabetes Res 2011: 349286, 2011.

6. Ambati BK, Nozaki M, Singh N, Takeda A, Jani PD, Suthar T, Albuquerque RJ, Richter E, Sakurai E, Newcomb MT, et al: Corneal avascularity is due to soluble VEGF receptor-1. Nature 443: 993-997, 2006.

7. Cursiefen C, Masli S, Ng TF, Dana MR, Bornstein P, Lawler J and Streilein JW: Roles of thrombospondin-1 and -2 in regulating corneal and iris angiogenesis. Invest Ophthalmol Vis Sci 45: 1117-1124, 2004.

8. Gao G and Ma J: Tipping the balance for angiogenic disorders. Drug Discov Today 7: 171-172, 2002.

9. Zhang SX and Ma JX: Ocular neovascularization: Implication of endogenous angiogenic inhibitors and potential therapy. Prog Retin Eye Res 26: 1-37, 2007.

10. Lu P,Li L, Kuno K, Wu Y,Baba T,Li YY,Zhang X and Mukaida N: Protective roles of the fractalkine/CX3CL1-CX3CR1 interactions in alkali-induced corneal neovascularization through enhanced antiangiogenic factor expression. J Immunol 108: 4283-4291, 2008.

11. Liu G, Lu P, Li L, Jin H, He X, Mukaida N and Zhang X: Critical role of SDF-1 $\alpha$-induced progenitor cell recruitment and macrophage VEGF production in the experimental corneal neovascularization. Mol Vis 18: 2128-2137, 2011.

12. Lu P, Li L, Liu G, van Rooijen N, Mukaida N and Zhang X: Opposite roles of CCR2 and CX3CR1 macrophages in alkali-induced corneal neovascularization. Cornea 28: 562-569, 2009.

13. Lu P, Li L, Liu G, Zhang X and Mukaida N: Enhanced experimental corneal neovascularization along with aberrant angiogenic factor expression in the absence of IL-1 receptor antagonist. Invest Ophthalmol Vis Sci 50: 4761-4768, 2009. 
14. Hoerster R, Muether PS, Vierkotten S, Schröder S, Kirchhof B and Fauser S: In-vivo and ex-vivo characterization of laser-induced choroidal neovascularization variability in mice. Graefes Arch Clin Exp Ophthalmol 250: 1579-1586, 2012.

15. Fujimura S, Takahashi H, Yuda K, Ueta T, Iriyama A, Inoue T, Kaburaki T, Tamaki Y, Matsushima K and Yanagi Y: Angiostatic effect of CXCR3 expressed on choroidal neovascularization. Invest Ophthalmol Vis Sci 53: 1999-2006, 2012.

16. Badr G, Badr BM, Mahmoud MH, Mohany M, Rabah DM and Garraud O: Treatment of diabetic mice with undenatured whey protein accelerates the wound healing process by enhancing the expression of MIP- $1 \alpha$, MIP-2, KC, CX3CL1 and TGF- $\beta$ in wounded tissue. BMC Immunol 13: 32, 2012.

17. Towner RA, Smith N, Saunders D, Henderson M, Downum K, Lupu F, Silasi-Mansat R, Ramirez DC, Gomez-Mejiba SE, Bonini MG, et al: In vivo imaging of immuno-spin trapped radicals with molecular magnetic resonance imaging in a diabetic mouse model. Diabetes 61: 2405-2413, 2012.

18. Yang Y, Mao D, Chen X, Zhao L, Tian Q, Liu C and Zhou BL: Decrease in retinal neuronal cells in streptozotocin-induced diabetic mice. Mol Vis 18: 1411-1420, 2012.

19. Semkova I, Fauser S, Lappas A, Smyth N, Kociok N, Kirchhof B, Paulsson M, Poulaki V and Joussen AM: Overexpression of FasL in retinal pigment epithelial cells reduces choroidal neovascularization. FASEB J 20: 1689-1691, 2006.

20. Livak KJ and Schmittgen TD: Analysis of relative gene expression data using real-time quantitative PCR and the 2(-Delta Delta C(T)) method. Methods 25: 402-408, 2001

21. Evans JR and Lawrenson JG: Antioxidant vitamin and mineral supplements for slowing the progression of age-related macular degeneration. Cochrane Database Syst Rev 7: CD000254, 2017.

22. Cheung LK and Eaton A: Age-related macular degeneration. Pharmacotherapy 33: 838-855, 2013.

23. Sin HP, Liu DT and Lam DS: Lifestyle modification, nutritional and vitamins supplements for age-related macular degeneration. Acta Ophthalmol 91: 6-11, 2013.

24. McCusker MM, Durrani K, Payette MJ and Suchecki J: An eye on nutrition: The role of vitamins, essential fatty acids, and antioxidants in age-related macular degeneration, dry eye syndrome, and cataract. Clin Dermatol 34: 276-285, 2016.

25. Stevens RJ, Coleman RL, Adler AI, Stratton IM, Matthews DR and Holman RR: Risk factors for myocardial infarction case fatality and stroke case fatality in type 2 diabetes: UKPDS 66 Diabetes Care 27: 201-207, 2004.

26. Chung SS, Ho EC, Lam KS and Chung SK: Contribution of polyol pathway to diabetes-induced oxidative stress. J Am Soc Nephrol 14 (8 Suppl 3): S233-S236, 2003.

27. Lee TS, Saltsman KA, Ohashi $\mathrm{H}$ and King GL: Activation of protein kinase $\mathrm{C}$ by elevation of glucose concentration: Proposal for a mechanism in the development of diabetic vascular complications. Proc Natl Acad Sci USA 86: 5141-5145, 1989.

28. Giacco F and Brownlee M: Oxidative stress and diabetic complications. Circ Res 107: 1058-1070, 2010

29. Schmidt AM, Yan SD, Wautier JL and Stern D: Activation of receptor for advanced glycation end products: A mechanism for chronic vascular dysfunction in diabetic vasculopathy and atherosclerosis. Circ Res 84: 489-497, 1999.

30. Kolluru GK, Bir SC and Kevil CG: Endothelial dysfunction and diabetes: Effects on angiogenesis, vascular remodeling, and wound healing. Int J Vasc Med 2012: 918267, 2012.

31. da Costa Pinto FA and Malucelli BE: Inflammatory infiltrate, VEGF and FGF-2 contents during corneal angiogenesis in STZ-diabetic rats. Angiogenesis 5: 67-74, 2002.

32. Zagon IS, Klocek MS, Griffith JW, Sassani JW, Komáromy AM and McLaughlin PJ: Prevention of exuberant granulation tissue and neovascularization in the rat cornea by naltrexone. Arch Ophthalmol 126: 501-506, 2008.

33. Waltenberger J, Lange J and Kranz A: Vascular endothelial growth factor-A-induced chemotaxis of monocytes is attenuated in patients with diabetes mellitus: A potential predictor for the individual capacity to develop collaterals. Circulation 102 : $185-190,2000$
34. Tchaikovski V, Olieslagers S, Böhmer FD and Waltenberger J: Diabetes mellitus activates signal transduction pathways resulting in vascular endothelial growth factor resistance of human monocytes. Circulation 120: 150-159, 2009.

35. Grossniklaus HE, Ling JX, Wallace TM, Dithmar S, Lawson DH, Cohen C, Elner VM, Elner SG and Sternberg P Jr: Macrophage and retinal pigment epithelium expression of angiogenic cytokines in choroidal neovascularization. Mol Vis 8: 119-126, 2002.

36. Greenberg JI, Shields DJ, Barillas SG, Acevedo LM, Murphy E, Huang J, Scheppke L, Stockmann C, Johnson RS, Angle N and Cheresh DA: A role for VEGF as a negative regulator of pericytes function and vessel maturation. Nature 456: 809-813, 2008.

37. Elner VM, Strieter RM, Elner SG, Baggiolini M, Lindley I and Kunkel SL: Neutrophil chemotactic factor (IL-8) gene expression by cytokine-treated retinal pigment epithelial cells. Am J Pathol 136: 745-750, 1990.

38. Losso JN, Truax RE and Richard G: Trans-resveratrol inhibits hyperglycemia-induced inflammation and connexin downregulation in retinal pigment epithelial cells. J Agric Food Chem 58: 8246-8252, 2010.

39. Yuan Z, Feng W, Hong J, Zheng Q, Shuai J and Ge Y: p38MAPK and ERK promote nitric oxide production in cultured human retinal pigmented epithelial cells induced by high concentration glucose. Nitric Oxide 20: 9-15, 2009.

40. Bento CF, Fernandes R, Matafome P, Sena C, Seiça R and Pereira P: Methylglyoxal-induced imbalance in the ratio of vascular endothelial growth factor to angiopoietin 2 secreted by retinal pigment epithelial cells leads to endothelial dysfunction. Exp Physiol 95: 955-970, 2010.

41. Villarroel M, García-Ramírez M, Corraliza L, Hernández C and Simó R: High glucose concentration leads to differential expression of tight junction proteins in human retinal pigment epithelial cells. Endocrinol Nutr 56: 53-58, 2009.

42. Tepper OM, Carr J, Allen RJ Jr, Chang CC, Lin CD, Tanaka R, Gupta SM, Levine JP, Saadeh PB and Warren SM: Decreased circulating progenitor cell number and failed mechanisms of stromal cell-derived factor-1alpha mediated bone marrow mobilization impair diabetic tissue repair. Diabetes 59: 1974-1983, 2010.

43. Gallagher KA, Liu ZJ, Xiao M, Chen H, Goldstein LJ, Buerk DG, Nedeau A, Thom SR and Velazquez OC: Diabetic impairments in NO-mediated endothelial progenitor cell mobilization and homing are reversed by hyperoxia and SDF-1 alpha. J Clin Invest 117: 1249-1259, 2007.

44. Jiraritthamrong C, Kheolamai P, U-Pratya Y, Chayosumrit M, Supokawej A, Manochantr S, Tantrawatpan C, Sritanaudomchai H and Issaragrisil S: In vitro vessel-forming capacity of endothelial progenitor cells in high glucose conditions. Ann Hematol 91: 311-320, 2012.

45. Cao C, Zhang H, Gong L, He Y and Zhang N: High glucose conditions suppress the function of bone marrow-derived endothelial progenitor cells via inhibition of the eNOS-caveolin-1 complex. Mol Med Report 5: 341-346, 2012.

46. Klein R, Klein BE and Moss SE: Diabetes, hyperglycemia, and age-related maculopathy. The beaver Dam Eye study. Ophthalmology 99: 1527-1534, 1992.

47. Song SJ, Youm DJ, Chang Y and Yu HG: Age-related macular degeneration in a screened South Korean population: Prevalence, risk factors, and subtypes. Ophthalmic Epidemiol 16: 304-310, 2009.

48. Choi JK, Lym YL, Moon JW, Shin HJ and Cho B: Diabetes mellitus and early age-related macular degeneration. Arch Ophthalmol 129: 196-199, 2011.

49. Topouzis F, Anastasopoulos E, Augood C, Bentham GC, Chakravarthy U, de Jong PT, Rahu M, Seland J, Soubrane G, Tomazzoli L, et al: Association of diabetes with age-related macular degeneration in the EUREYE study. Br J Ophthalmol 93: 1037-1041, 2009.

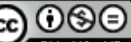

This work is licensed under a Creative Commons Attribution-NonCommercial-NoDerivatives 4.0 International (CC BY-NC-ND 4.0) License. 